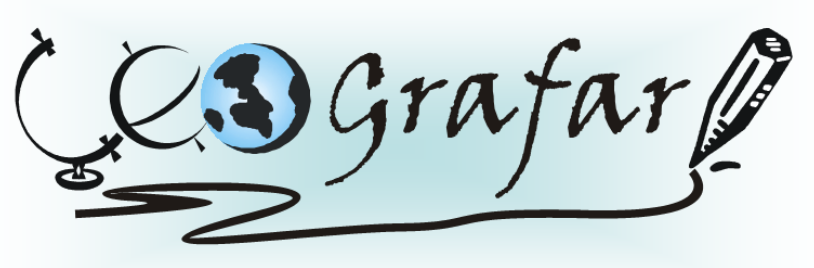

Revista Eletrônica do Programa de Pós-Graduação em Geografia - UFPR

\title{
FLORÍSTICA DE UM REMANESCENTE URBANO DE FLORESTA OMBRÓFILA MISTA ALUVIAL, CURITIBA, PARANÁ
}

\section{FLORISTIC OF A URBAN REMNANT OF RIPARIAN OMBROFILA MISTA FOREST, CURITIBA, PARANA}

\section{(Recebido em 29.01.2014; Aceito em: 26.06.2014)}

\author{
Joema Carvalho \\ Doutoranda em Engenheria Florestal \\ Universidade Federal do Paraná \\ Curitiba, PR, Brasil \\ e-mail: joemacarvalho@gmail.com
}

Ana Marise Auer

Prof. Dra. do Curso de Engenharia

Ambiental e Sanitária

Faculdade Bagozzi

Curitiba, PR, Brasil

e-mail: ana.auer@gmail.com

Lauri Amândio Schorn

Prof. Dr. do curso de Engenharia Florestal Fundação Universidade Regional de Blumenau

Blumenau, SC, Brasil e-mail: lauri.amandio@terra.com.br

Nei Sebastião Braga Gomes

Prof. Dr. do curso de Engenharia Florestal

Universidade Federal do Acre Rio Branco, AC, Brasil e-mail: bragagomes@gmail.com

Elaine de Cacia de Lima Frick Prof. Msc. do Departamento de Geografia Universidade Federal do Paraná Curitiba, PR, Brasil e-mail: elainecacia@ufpr.br 


\section{RESUMO}

Realizou-se um estudo fitossociológico nos compartimentos superior e inferior de um remanescente da Floresta Ombrófila Mista Aluvial, compreendido na área do Bosque de Portugal, uma unidade de conservação municipal da cidade de Curitiba, no Estado do Paraná. Foram alocadas sistematicamente 15 unidades amostrais dimensionadas em $5 \mathrm{~m} \times 10 \mathrm{~m}$, nas quais foram mensurados e identificados todos os indivíduos com perímetro igual ou superior a $15 \mathrm{~cm}$, à altura do peito (PAP); no interior dessas parcelas foram alocadas subparcelas de $5 \mathrm{~m} \times 5 \mathrm{~m}$ para a mensuração dos indivíduos com perímetro inferior a $15 \mathrm{~cm}$ à altura do peito (PAP) que apresentaram altura maior que $1,30 \mathrm{~m}$. No compartimento superior foram encontradas 34 espécies arbóreas pertencentes a 27 gêneros e 18 famílias. Sebastiania commersoniana foi à espécie mais importante da comunidade, seguida por Schinus terebinthifolius, indivíduos mortos, Sebastiania brasiliensis, Allophylus edulis. No compartimento inferior foram encontradas 31 espécies, 25 gêneros e 18 famílias, sendo aquela de maior importância Allophylus edulis, Eugenia uniflora, Sebastiania brasiliensis e Ligustrum lucidum. Os índices de diversidade relativamente baixos indicam uma comunidade florística composta por poucas espécies. A presença de espécies exóticas invasoras como Ligustrum lucidum, Morus nigra e Pittosporum undulatum, decorrente da interferência antrópica urbana, comprometem a estrutura, composição florística e dinâmica do remanescente estudado.

Palavras-chave: fitossociologia, arbórea, compartimento superior e inferior.

\section{ABSTRACT}

A phytosociological study of the upper and lower compartments were performed in an alluvial forest transect of the Portugal Park in Curitiba, Paraná, Southern Brazil. 15 sample units of $10 \mathrm{~m} \times 5 \mathrm{~m}$ were measured of species individuals with a breast hight perimeter - BHP equal or larger than $15 \mathrm{~cm}$. Sub-parcels of $5 \mathrm{~m} \times 5 \mathrm{~m}$ were also established to assess species individuals with a BHP smaller than $15 \mathrm{~cm}$ and a hight bigger than $1,30 \mathrm{~m}$. 34 tree species, from 27 genres and 18 families were found in the upper compartment of this urban remnant of riparian forest. The most important species found in upper compartment was Sebastiania commersonina, followed by Schinus terebinthifolius, Sebastiania brasiliensis, Allophylus edulis, Machaerium paraguariensis and Rhamnus sphaerosperma. In the lower compartment were found 31 species, 25 genres and 18 families. The most important speceis was Allophylus edulis, followed by Eugenia uniflora, Sebastiania brasiliensis and Ligustrumlucidum. The structure of the forest is considered as highly homogeneous due to its very low diversity index, dominated by a single species, demonstrating the restrictive character of the riparian environments, conditioned by water saturation conditions. The presence of invasive alien species like Ligustrum lucidum, Morus nigra, Pittosporum undulatum denotes the anthropic interference of the forest, with negative impacts its structure, floristic composition and dynamics.

Keywords: phytosociology, tree, upper and lower compartments. 


\section{INTRODUÇÃO}

O Bosque de Portugal, unidade de conservação municipal criada pelo Decreto № 848/1995 em homenagem a colonização portuguesa, situa-se em Curitiba, no Estado do Paraná. Sua finalidade é a preservação da vegetação, educação ambiental, recreação, cultura, esporte e lazer (SMMA, 1995; OLIVEIRA, 1996). É uma das poucas áreas verdes urbanas no Brasil, que contempla um remanescente florestal com composição florística e estrutura semelhantes a remanescentes encontrados em áreas naturais. Junto as demais unidades de conservação municipais de Curitiba, como o Parque Barigui (KOZERA et al., 2006a e 2006b), Bosque João Paulo II (ROSEIRA, 1990) e Bosque da Fazendinha (SELUNIASKI; ACRA, 2010) tem como objetivo a proteção dos recursos naturais existentes, manutenção da qualidade de vida e proteção do interesse comum de todos os habitantes (SMMA, 2000). Além destes, verifica-se o Parque do Ingá (PAULA; FERREIRA, 2005) em Maringá (Paraná), do Parque Municipal João José Theodoro da Costa Neto em Lages (Santa Catarina), do Bosque dos Italianos, do Bosque dos Alemães, do Bosque São José, do Bosque dos Guarantã e do Bosque da Paz de Campinas (São Paulo) (DACANAL et al., 2010).

A vegetação presente no Bosque de Portugal encontra-se na área de dispersão da Floresta Ombrófila Mista Aluvial que integra o Bioma Mata Atlântica (IBGE, 2012). Essa tipologia se desenvolve nas margens de cursos d'água, percorrendo terrenos de geomorfologia plana até suave-ondulada (RODERJAN et al., 2002). Regionalmente, esse tipo de vegetação é característico dos cursos d'água da bacia do rio Iguaçu, sendo composta por um pequeno número de árvores de porte médio caracterizando uma fisionomia homogênea (KLEIN; HATSCHBACH, 1962).

De maneira geral, a Floresta Ombrófila Mista Aluvial tem como espécie dominante a Araucaria angustifolia, que está associada a ecotipos que variam de acordo com as altitudes dos flúvios (IBGE, 2012). Para Leite (1994), a orla das florestas aluviais é, em geral, composta por espécies heliófitas, destacando-se Myrcia bombycina, Myrceugenia euosma, Calyptranthes concina, Sebastiania commersoniana, Lithraea brasiliensis, Schinus terebinthifolius, Ilex spp., Podocarpus lambertii e Drimys brasiliensis. Não obstante, as espécies menos exigentes de luz como Ocotea odorifera, Allophylus edulis, Handroanthus albus, Prunus sellowii, 
Capsicodendron dinisii, Ocotea porosa, Blepharocalyx salicifolius e Matayba elaeagnoides ocorrem no interior dos capões (KLEIN; HATSCHBACH,1962). $\mathrm{Na}$ maioria dos remanescentes desta tipologia o solo é revestido por um tapete de gramíneas rizomatosas (geófitas), principalmente das espécies Xonopus compressus e Pseudochinolaena polystachya. Além destas, podem ocorrer Luehea divaricata e os gêneros Cryptocarya e Nectandra (IBGE, 2012).

As florestas aluviais ou ciliares, em grande parte das situações naturais do Brasil, encontraram condições para o seu desenvolvimento no período geológico do Holoceno, sendo de um tempo, portanto, relativamente recente. Possuem, assim, uma estrutura e funcionalidade ecossistêmica aparentemente similar, apesar das dimensões continentais do território brasileiro. No entanto, essas florestas diferem entre si pela sua composição taxonômica, domínio, região e altitude em que são encontradas (AB'SABER, 2001).

No ambiente urbano os remanescentes florestais contribuem com o equilíbrio microclimático, são responsáveis pela manutenção de mananciais e asseguram a estabilidade geomorfológica; funcionam ainda como corredores ecológicos, sendo suporte para as cadeias tróficas e interações entre os organismos vivos aquáticos e terrestres, favorecendo a biodiversidade nativa. Também contribuem com a qualidade ambiental e de vida da sociedade, pois configuram como alternativas para o contato direto da população com os ambientes naturais (DANTAS; SOUZA, 2004; LIRA-FILHO; MEDEIROS, 2006). É nesse ambiente que a área de estudo está inserida e, portanto, tem uma expressiva importância ambiental.

Nesse contexto, o presente trabalho foi realizado com o objetivo de analisar a estrutura fitossociológica e a composição florística do compartimento superior e inferior do remanescente urbano de Floresta Ombrófila Mista Aluvial presente no Bosque de Portugal.

\section{MÉTODO}

Curitiba está localizada no Primeiro Planalto do Paraná na latitude $25^{\circ} 25^{\prime} 40^{\prime \prime}$ $S$ e longitude $49^{\circ} 16^{\prime} 23^{\prime \prime} \mathrm{W}$, em uma altitude média de 934,6 m acima do nível do mar. O clima é tipo $\mathrm{Cfb}$, (clima temperado ou subtropical) úmido, sem estação seca, com verões frescos e invernos com geadas frequentes e ocasionais precipitações de 
neve, com temperaturas médias de $22^{\circ} \mathrm{C}$ no verão e $10^{\circ} \mathrm{C}$ no inverno (FANINI, 2008; Figura 1).

Bosque de Portugal, com área de $20.850 \mathrm{~m}^{2}$, abriga um remanescente urbano de Floresta Ombrófila Mista Aluvial o qual ladeia o rio Tarumã. Está localizado no Bairro Jardim Social, no setor nordeste da cidade de Curitiba, estado do Paraná, delimitado pelas coordenadas geográficas $25^{\circ} 24^{\prime} 52,83^{\prime \prime}$ S e $49^{\circ} 13^{\prime} 59,87^{\prime \prime}$ W, nas calhas do córrego Tarumã (SMMA, 2013; Figura 1).

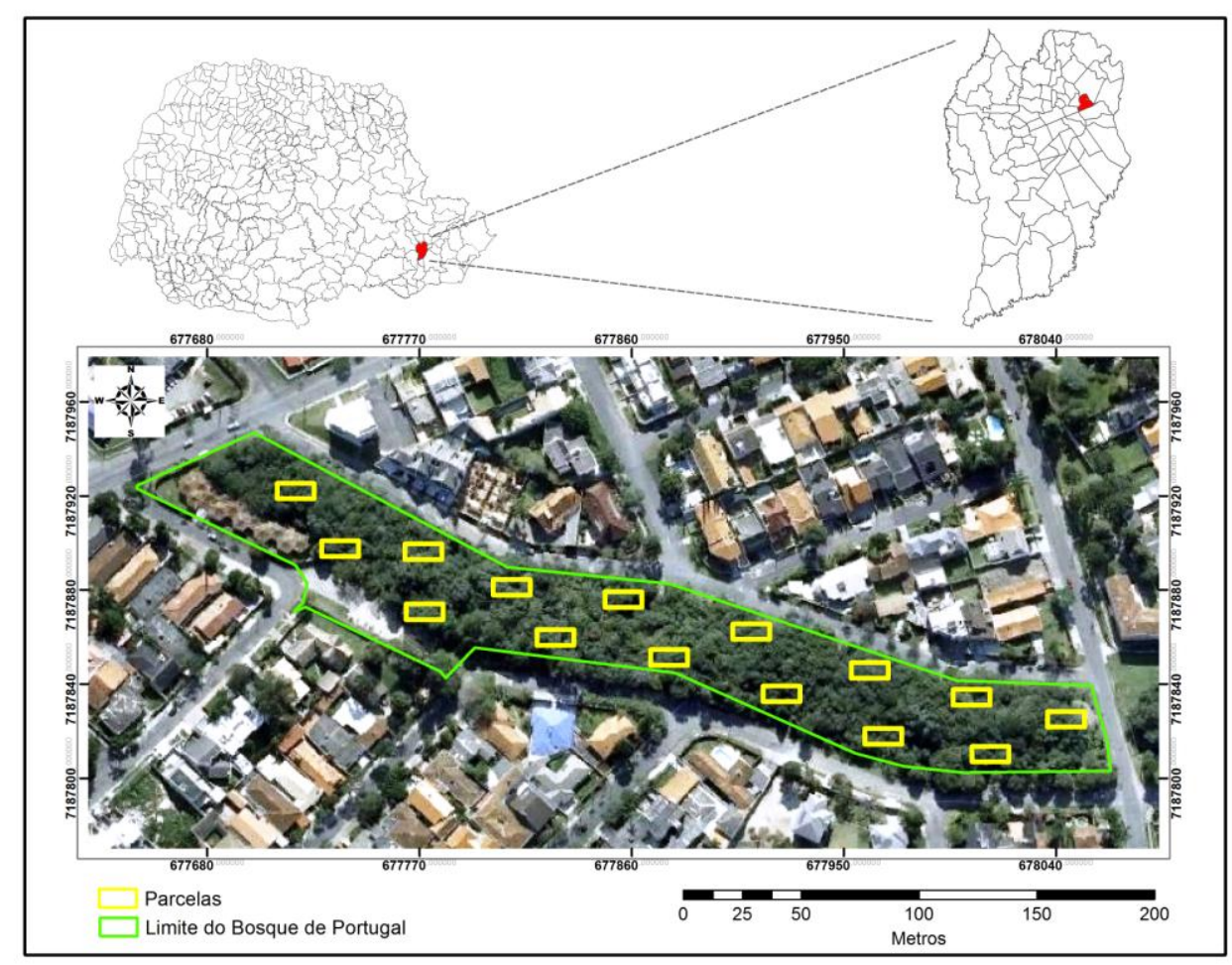

Figura 1. Localização da área de estudos e posicionamento das parcelas de um remanescente urbano de floresta aluvial, Curitiba, PR.

Para a amostragem do compartimento superior da floresta foram alocadas 15 parcelas de $5 \mathrm{~m} \times 10 \mathrm{~m}$, dispostas de modo sequencial e posicionadas paralelamente ao rio Tarumã, onde foram avaliados todos os indivíduos arbóreos e arbustivos com perímetro à altura do peito (PAP) igual ou superior a $15 \mathrm{~cm}$. No interior de cada parcela foi alocada uma subparcela com dimensões de $5 \mathrm{~m} \times 5 \mathrm{~m}$ para a avaliação do compartimento inferior da floresta. Nesta subparcela foram mensurados todos os indivíduos arbóreos e arbustivos com PAP inferior a $15 \mathrm{~cm}$ e altura superior a $1,3 \mathrm{~m}$.

Os parâmetros fitossociológicos relativos de densidade, frequência, 
dominância, e o de valor de importância foram calculados conforme MuellerDombois e Ellenberg (1974). Além desses, foi obtido o Índice de Diversidade de Shannon (H') (MAGURRAN, 1989).

A identificação dos indivíduos arbóreos foi realizada in loco, por especialista da área. Coletou-se o material vegetal dos indivíduos que não foi possível a identificação in loco, posteriormente, este foi identificado por comparação com exsicatas depositadas no Herbário do Curso de Engenharia Florestal (EFC) da Universidade Federal do Paraná com apoio do professor responsável por este herbário.

Organizou-se sistematicamente as famílias de acordo com APG III Angiosperm Phylogeny Group (2009) e a confirmação dos nomes científicos foi efetivada no Herbarium virtual Missouri Botanical Garden.

\section{RESULTADOS}

O compartimento superior está conformado por 34 espécies arbóreas $(64,2 \%$ do total) pertencentes a 27 gêneros e 18 famílias e o inferior, 31 espécies (58,5\% do total), 25 gêneros e 18 famílias, totalizando 53 espécies nos dois compartimentos. Observou-se que 23 espécies (43,4\% do total) são exclusivas do compartimento superior, 19 espécies (35,8\% do total) são exclusivas do compartimento inferior e 11 espécies (20,8\% do total) ocorrem em ambos os compartimentos (Quadro 1 ).

Quadro 1. Espécies encontradas nos compartimentos superior e inferior em um remanescente urbano de uma floresta aluvial, Curitiba, Paraná.

\begin{tabular}{|c|c|c|c|}
\hline Família & Espécie & Superior & Inferior \\
\hline \multirow[t]{2}{*}{ ANACARDIACEAE } & Lithraea brasiliensis Marchand & $\mathrm{x}$ & \\
\hline & Schinus terebinthifolius Raddi & $\mathrm{x}$ & \\
\hline ASTERACEAE & Gochnatia polymorpha (Less.) Cabrera & $\mathrm{x}$ & \\
\hline BIGNONIACEAE & Jacaranda puberula Cham. & $\hat{x}$ & \\
\hline CANELLACEAE & Capsicoden drondinisii (Schwacke) Occhioni & & $\mathrm{x}$ \\
\hline \multirow[t]{2}{*}{ EUPHORBIACEAE } & $\begin{array}{l}\text { Sebastiania commersoniana (Baillon) L. B. Sm. } 8 \\
\text { Downs }\end{array}$ & $\mathrm{x}$ & $x$ \\
\hline & $\begin{array}{l}\text { Sebastiania brasiliensis Sprengel } \\
\text { Bernardia pulchella Mull. Arg. }\end{array}$ & $\mathrm{x}$ & $\begin{array}{l}x \\
x\end{array}$ \\
\hline \multirow[t]{6}{*}{ FABACEAE (Faboidea) } & Dalbergia brasiliensis Vogel & & $\mathrm{x}$ \\
\hline & Dalbergia sp. & & $\mathrm{X}$ \\
\hline & Lonchocarpus muehlbergianus Hassl. & $\mathrm{X}$ & \\
\hline & Machaerium paraguariense Hassl. & $x$ & \\
\hline & Machaerium stipitatum (DC.) Vogel & $\mathrm{x}$ & $\mathrm{x}$ \\
\hline & Senna multijuga (Rich.) H.S. Irwin \&Barneby & & $\mathrm{x}$ \\
\hline
\end{tabular}




\begin{tabular}{|c|c|c|c|}
\hline LAURACEAE & Ocotea pulchella Mart. & $\mathrm{X}$ & \\
\hline MALVACEAE & Luehea divaricata Mart. & $\mathrm{X}$ & \\
\hline MELASTOMATACEAE & Miconia $s p$ & & $\mathrm{x}$ \\
\hline MORACEAE & Morus nigra L. & & $\mathrm{X}$ \\
\hline \multirow[t]{11}{*}{ MYRTACEAE } & Calyptrantes concinna DC. & $\mathrm{X}$ & $\mathrm{x}$ \\
\hline & Eugenia uniflora L. & $\mathrm{X}$ & $\mathrm{x}$ \\
\hline & Eugenia uruguayensis Cambess. & $\mathrm{X}$ & $\mathrm{x}$ \\
\hline & Gomidesia palustris (DC.) D. Legrand & $x$ & \\
\hline & Myrcia hatschbachii D. Legrand & & $\mathrm{x}$ \\
\hline & Myrcia obtecta (O. Berg) Kiaersk. & $\mathrm{X}$ & $\mathrm{x}$ \\
\hline & Myrciaria tenella (DC.) O. Berg. & & $\mathrm{X}$ \\
\hline & Myrrhinium atropurpureum Schott & $\mathrm{x}$ & \\
\hline & $\begin{array}{l}\text { Pimenta pseudocaryophyllus (Gomes) L. R } \\
\text { Landrun }\end{array}$ & $\mathrm{x}$ & $\mathrm{x}$ \\
\hline & Psidium cattleianum Sabine & $\mathrm{x}$ & \\
\hline & $\begin{array}{l}\text { Pimenta pseudocaryophyllus (Gomes) L. R } \\
\text { Landrun }\end{array}$ & & $\mathrm{x}$ \\
\hline MYRSINACEAE & Rapanea ferruginea (Ruiz \& Pav.) Mez & $\mathrm{x}$ & $\mathrm{x}$ \\
\hline OLEACEAE & Ligustrum lucidum W. T. Aiton & $\mathrm{x}$ & $\mathrm{x}$ \\
\hline PITTOSPORACEAE & Pittosporum undulatum Vent. & & $\mathrm{X}$ \\
\hline PODOCARPACEAE & Podocarpus lambertii Klotzsch ex Endl. & & $\mathrm{X}$ \\
\hline PROTEACEAE & Roupala brasiliensis Klotzsch. & & $\mathrm{X}$ \\
\hline RHAMNACEAE & Rhamnus sphaerosperma Sw. & $\mathrm{x}$ & \\
\hline ROSACEAE & Prunus brasiliensis (Cham. \&Schltdl.) Dietrich & $\mathrm{x}$ & $\mathrm{x}$ \\
\hline RUBIACEAE & Guettarda uruguensis Cham. \& Schltdl. & $\mathrm{X}$ & \\
\hline RUTACEAE & Zanthoxylum rhoifolium Lam. & $\mathrm{X}$ & \\
\hline \multirow[t]{2}{*}{ SALICACEAE } & Casearia decandra Jacq. & & $\mathrm{X}$ \\
\hline & Xylosma pseudosalzmanii Sleumer & & $\mathrm{x}$ \\
\hline \multirow[t]{2}{*}{ SAPINDACEAE } & $\begin{array}{l}\text { Allophylus edulis (A. Saint-Hilaire, Cambessedes } \\
\text { \& A Jussieu) Radlkofer }\end{array}$ & $\mathrm{x}$ & $x$ \\
\hline & Cupania vernalis Cambess. & $\mathrm{X}$ & \\
\hline SALICACEAE & Xylosma pseudosalzmanii Sleumer & $\mathrm{x}$ & \\
\hline SIMAROUBACEAE & Picramnia parvifolia Engl & & $\mathrm{x}$ \\
\hline \multirow[t]{2}{*}{ SOLANACEAE } & Solanum pseudoquina A. St.-Hilaire & & $\mathrm{x}$ \\
\hline & Solanum sanctae-catharinae Dunal & & $\mathrm{x}$ \\
\hline SYMPLOCACEAE & Symplocos uniflora (Pohl) Benth. & $\mathrm{X}$ & \\
\hline VERBENACEAE & Duranta vestita Cham. & & $X$ \\
\hline WINTERACEAE & Drymis brasiliensis Miers & $\mathrm{x}$ & \\
\hline \multirow[t]{4}{*}{ Indeterminada } & Indeterminada 1 & $\mathrm{x}$ & \\
\hline & Indeterminada 2 & $\mathrm{x}$ & \\
\hline & Indeterminada 3 & $\mathrm{x}$ & \\
\hline & Indeterminada 4 & $\mathrm{x}$ & \\
\hline
\end{tabular}

O índice de diversidade de Shannon $\left(\mathrm{H}^{\prime}\right)$ encontrado para o compartimento superior foi 2,23 nats. Ind ${ }^{-1}$ e para o inferior foi de 2,29 nats. Ind ${ }^{-1}$. $O$ índice de similaridade Sorensen entre os dois estratos foi de $31,8 \%$.

No compartimento superior Sebastiania commersoniana apresentou os maiores valores para todos os parâmetros analisados. Esta espécie junto a Schinus terebinthifolius, indivíduos mortos, Sebastiania brasiliensis, Allophylus edulis compreenderam os maiores valores para densidade $(60 \%$ do total) e frequência relativas e valor de importância (169,3 do total). Sebastiania commersoniana, 
Schinus terebinthifolius, Machaerium paraguariense, Allophylus edulis e Sebastiania brasiliensis foram dominantes na comunidade, totalizando juntas $66,1 \%$ do total (Tabela 1).

Tabela 1. Parâmetros fitossociológicos do compartimento superior de um remanescente urbano de floresta aluvial, Curitiba, PR. DR - densidade relativa (\%), FR - frequência relativa (\%), DoR - dominância relativa (\%), VI - Valor de importância (\%).

\begin{tabular}{|c|c|c|c|c|}
\hline Espécies & DR & DoR & FR & VI \\
\hline Sebastiania commersoniana & 34,36 & 40,59 & 14,29 & 89,24 \\
\hline Schinus terebinthifolius & 4,62 & 9,95 & 7,14 & 21,71 \\
\hline Indivíduos mortos & 8,72 & 2,09 & 10,20 & 21,01 \\
\hline Sebastiania brasiliensis & 7,18 & 4,16 & 8,16 & 19,50 \\
\hline Allophylus edulis & 5,13 & 5,57 & 7,14 & 17,84 \\
\hline Machaerium paraguariense & 3,59 & 5,80 & 3,06 & 12,45 \\
\hline Rhamnus sphaerosperma & 4,62 & 1,84 & 5,10 & 11,56 \\
\hline Guettarda uruguensis & 6,15 & 1,18 & 4,08 & 11,41 \\
\hline Luehea divaricata & 3,59 & 3,41 & 2,04 & 9,04 \\
\hline Prunus brasiliensis & 2,05 & 1,00 & 4,08 & 7,13 \\
\hline Zanthoxylum rhoifolium & 1,54 & 1,80 & 3,06 & 6,40 \\
\hline Xylosma pseudosalzmanii & 2,05 & 0,91 & 3,06 & 6,02 \\
\hline Eugenia uniflora & 2,05 & 0,73 & 3,06 & 5,84 \\
\hline Rapanea ferruginea & 1,03 & 2,57 & 2,04 & 5,64 \\
\hline Cupania vernalis & 0,51 & 3,94 & 1,02 & 5,47 \\
\hline Gochnatia polymorpha & 1,03 & 2,20 & 2,04 & 5,27 \\
\hline Eugenia uruguayensis & 2,05 & 0,74 & 2,04 & 4,83 \\
\hline Indeterminada 2 & 0,51 & 2,10 & 1,02 & 3,63 \\
\hline Indeterminada 1 & 0,51 & 1,91 & 1,02 & 3,44 \\
\hline Indeterminada 4 & 1,03 & 1,34 & 1,02 & 3,39 \\
\hline Jacaranda puberula & 0,51 & 1,24 & 1,02 & 2,77 \\
\hline Drymis brasiliensis & 0,51 & 0,96 & 1,02 & 2,49 \\
\hline Indeterminada 3 & 0,51 & 0,88 & 1,02 & 2,41 \\
\hline Lonchocarpus muehlbergianus & 0,51 & 0,71 & 1,02 & 2,24 \\
\hline Lithraea brasiliensis & 0,51 & 0,42 & 1,02 & 1,95 \\
\hline Ocotea pulchella & 0,51 & 0,33 & 1,02 & 1,86 \\
\hline Symplocos uniflora & 0,51 & 0,31 & 1,02 & 1,84 \\
\hline Calyptranthes concinna & 0,51 & 0,26 & 1,02 & 1,79 \\
\hline Gomidesia palustris & 0,51 & 0,22 & 1,02 & 1,75 \\
\hline
\end{tabular}


Continuação

\begin{tabular}{lcccc} 
Myrrhinium atropurpureum & 0,51 & 0,22 & 1,02 & 1,75 \\
Machaerium stipitatum & 0,51 & 0,20 & 1,02 & 1,73 \\
\hline Psidium cattleianum & 0,51 & 0,16 & 1,02 & 1,69 \\
Myrcia obtecta & 0,51 & 0,10 & 1,02 & 1,63 \\
Pimenta pseudocaryophyllus & 0,51 & 0,10 & 1,02 & 1,63 \\
Ligustrum lucidum & 0,51 & 0,06 & 1,02 & 1,59 \\
\hline Total & $\mathbf{1 0 0}$ & $\mathbf{1 0 0}$ & $\mathbf{1 0 0}$ & $\mathbf{3 0 0}$ \\
\hline
\end{tabular}

No compartimento inferior Allophylus edulis, seguida por Ligustrum lucidum, Prunus brasiliensis, Eugenia uniflora, Sebastiania brasiliensis apresentaram os maiores valores para densidade relativa $(75,8 \%$ do total). A relação foi semelhante para os valores de dominância, as cinco primeiras espécies perfazem juntas 56,7\% do total. Ainda, Sebastiania brasiliensise apresentou maior frequência, seguida por Pittosporum undulatum, Eugenia uniflora e Allophylus edulis, sendo esta a espécie mais importante do compartimento inferior, juntamente com a Eugenia uniflora, Sebastiania brasiliensis, Ligustrum lucidum e Prunus brasiliensis (168,87\% do total) (Tabela 2).

Tabela 2. Parâmetros fitossociológicos do compartimento inferior de um remanescente urbano de floresta aluvial, Curitiba, PR. DR - densidade relativa (\%), FR - frequência relativa (\%), DoR - dominância relativa (\%), VI - valor de importância (\%).

\begin{tabular}{lrrrr}
\hline \multicolumn{1}{c}{ Espécies } & \multicolumn{1}{c}{ DR } & DoR & \multicolumn{1}{c}{ FR } & \multicolumn{1}{c}{ VI } \\
\hline Allophylus edulis & 33,84 & 23,57 & 7,27 & 64,68 \\
Eugenia uniflora & 8,84 & 11,43 & 9,09 & 29,36 \\
Sebastiania brasiliensis & 8,84 & 7,95 & 10,91 & 27,70 \\
Ligustrum lucidum & 14,90 & 8,30 & 3,64 & 26,84 \\
Prunus brasiliensis & 9,35 & 5,49 & 5,45 & 20,29 \\
Pittosporum undulatum & 2,27 & 4,60 & 9,09 & 15,96 \\
Dalbergia brasiliensis & 6,32 & 7,37 & 1,82 & 15,51 \\
Myrcia hatschbachii & 6,32 & 2,81 & 1,82 & 10,95 \\
Sebastiania commersoniana & 1,26 & 2,10 & 7,27 & 10,63 \\
Bernardia pulchella & 0,50 & 5,36 & 1,82 & 7,68 \\
Myrciaria tenella & 0,76 & 1,38 & 3,64 & 5,78 \\
Morus nigra & 0,50 & 1,16 & 3,64 & 5,30 \\
Casearia decandra & 0,50 & 2,86 & 1,82 & 5,18 \\
& & & & Continua
\end{tabular}


Continuação

\begin{tabular}{lllll} 
Capsicodendron dinisii & 0,26 & 2,90 & 1,82 & 4,98 \\
\hline Rapanea ferruginea & 0,50 & 0,67 & 3,64 & 4,81 \\
Xylosma pseudosalzmanii & 0,50 & 2,10 & 1,82 & 4,42 \\
Duranta vestita & 0,50 & 1,88 & 1,82 & 4,42 \\
Indivíduos mortos & 0,26 & 1,88 & 1,82 & 3,96 \\
Eugenia uruguayensis & 0,26 & 1,61 & 1,82 & 3,69 \\
Machaerium stipitatum & 0,50 & 0,98 & 1,82 & 3,30 \\
Luehea divaricata & 0,26 & 0,80 & 1,82 & 2,88 \\
Podocarpus lambertii & 0,50 & 0,31 & 1,82 & 2,63 \\
Senna multijuga & 0,50 & 0,22 & 1,82 & 2,54 \\
Miconia sp. & 0,26 & 0,45 & 1,82 & 2,53 \\
Solanum pseudoquina & 0,26 & 0,45 & 1,82 & 2,53 \\
Myrcia obtecta & 0,26 & 0,40 & 1,82 & 2,48 \\
Picramnia parvifolia & 0,26 & 0,31 & 1,82 & 2,39 \\
Solanum sanctae-catharinae & 0,26 & 0,31 & 1,82 & 2,39 \\
Pimenta pseudocaryophyllus & 0,26 & 0,22 & 1,82 & 2,30 \\
Roupala brasiliensis & 0,26 & 0,13 & 1,82 & 2,21 \\
\hline Total & 100 & 100 & 100 & 300 \\
\hline
\end{tabular}

\section{DISCUSSÕES}

As formações aluviais possuem baixa diversidade, característica de solos hidromórficos, dada a seletividade imposta por esse tipo de regime hídrico (CURCIO et al., 2006).

A afirmação acima é evidenciada nos resultados relativos ao Índice de Diversidade de Shannon $\left(\mathrm{H}^{\prime}\right)$ da comunidade florestal avaliada. O valor encontrado no compartimento superior da floresta do Bosque de Portugal foi superior aos resultados de outros trabalhos realizados nos mesmo compartimentos em formações aluviais da Floresta Ombrófila Mista da Região Metropolitana de Curitiba, Estado do Paraná. No Rio Pequeno em São José dos Pinhais, Bufren (1997) verificou 1,88 nats. Ind ${ }^{-1}$ e Barddal et al. (2004a), no Arroio Saldanha, afluente do Rio Barigui, no Município de Araucária, encontrou 1,59 nats. Ind ${ }^{-1}$. Quanto ao compartimento inferior da floresta do presente estudo, o Índice de Shannon encontrado foi semelhante aos resultados daqueles mesmos autores, 2,49 nats.ind ${ }^{-1}$ (BARDDAL et al., 2004b) e 2,47 nats. ind ${ }^{-1}$ (BUFREN, 1997). 
Quando o Índice de Diversidade obtido para a comunidade vegetal do presente estudo é comparado com os Índices de Diversidade de formações montanas da Floresta Ombrófila Mista, os valores obtidos em florestas aluviais são inferiores. Em remanescente da Floresta Ombrófila Mista localizado no Parque Municipal João José Theodoro da Costa Neto - PARNAMUL, no Município de Lages em Santa Catarina, observou-se 3,05 nats.ind-1 (KLAUBERG et al., 2010), e em outro remanescente da mesma tipologia no Município de Nova Prata no Rio Grande do Sul verificou-se 3,00 nats.ind-1 (NASCIMENTO et al., 2001).

Estudos realizados no compartimento superior de outros remanescentes florestais aluviais situados na Região Metropolitana de Curitiba apontam Sebastiania commersoniana a espécie mais densa, expressando valores significativos para o parâmetro como, 60,3\% do total (BARDDAL et al., 2004a) e 48\%, do total (ZILLER; HATSCHBACH, 1993). Esta espécie ocorre preferencialmente em formações pioneiras, o que a caracteriza como uma espécie típica de ambientes que frequentemente sofrem os efeitos da saturação hídrica do solo (BARDDAL, 2006).

Sebastiania commersoniana foi a espécie mais importante no compartimento superior da floresta estudada, seguida por Schinus terebinthifolius e indivíduos mortos. Os valores foram semelhantes a outras florestas aluviais da região estudada, como é o caso de Carvalho et al. (2009) e Barddal et al. (2004a,b) no Arroio Saldanha, afluente do Rio Barigui, no Município de Araucária, Paraná e por Ziller e Hatschbach (1993). Tais espécies são adaptadas ao regime hídrico de saturação periódica do solo. O valor de importância é representado em $80 \%$ por uma única espécie, o que caracteriza um ambiente homogêneo com predomínio de poucas espécies, diferente da Floresta Ombrófila Mista Montana. Esta, hoje rara formação, está conservada no Parque das Araucárias, município de Guarapuava, no Paraná, e expressa Araucaria angustifolia (29,4\%) seguida por Campomanesia xanthocarpa $(15,5 \%)$ como as espécies mais importantes desse tipo florestal (CORDEIRO; RODRIGUES, 2007).

A mortalidade observada está relacionada, possivelmente, ao alagamento em detrimento do recrutamento, distúrbio que afeta toda a comunidade (DAMASCENO JÚNIOR et al., 2004; GUIMARÃES et al., 2008). Este fato pode, também, estar relacionado a fatores antrópicos, como a retirada seletiva de madeira ou simplesmente por atos de depredação. Contudo, entende-se que a mortalidade 
disponibilizará maior quantidade de luz e, portanto, possibilitará o crescimento de espécies pioneiras (SILVA et al., 2011).

A espécie mais importante do compartimento inferior da floresta estudada, pelo presente trabalho, foi Allophylus edulis. Os resultados verificados por Barddal et al. (2004b) e Carvalho et al. (2009), em compartimentos inferiores da mesma tipologia demonstraram semelhante relação, $56,7 \%$ e $31,4 \%$ respectivamente.

Ligustrum lucidum, considerada espécie exótica invasora (IAP, 2006; GISP, 2005), apresentou alto valor de importância no compartimento inferior da floresta estudada, decorrente de sua elevada densidade. Situação semelhante foi verificada em estudo realizado no Parque Estadual João Paulo II, localizado na região central de Curitiba (ROSEIRA, 1990).

Ainda, na comunidade estudada observou-se Pittosporum undulatum, com densidade significativa no compartimento inferior, e Morus nigra. Essas espécies também são consideradas exóticas invasoras (IAP, 2006; GISP, 2005), por ocorrem em área fora de seu limite de ocorrência natural, se adaptando e se reproduzindo eficazmente, tornando-se dominantes, e assim alterando processos ecológicos naturais. A dispersão de espécies exóticas é, na maioria dos casos, promovida pela atividade humana (INSTITUTO DE RECURSOS MUNDIAIS; UNIÃO MUNDIAL PARA A NATUREZA; PROGRAMA DAS NAÇÕES UNIDAS PARA O MEIO AMBIENTE, 1992).

As consequências da invasão biológica de espécies vegetais exóticas em remanescentes naturais são verificadas em todo território nacional. Em um trabalho desenvolvido no Parque Estadual da Lagoa Azul em Campo Mourão, Paraná, os autores observaram-se que a dispersão dessas espécies exóticas invasoras é potencializada quando as mesmas possuem dispersão zoocórica, como é o caso de Eriobotrya japonica e Houvenia dulces (VIGILATO; ZAMPAR, 2011). Um estudo desenvolvido no Parque Nacional de Brasília, em Goiânia, Goiás (SANTANA; ENCINAS, 2005) e no rio Guandu, na Baixada Fluminense, RJ (SALAMENE et al, 2011) ressaltam a presença destas espécies em detrimento das nativas.

Sebastiania commersoniana, presente no compartimento superior, e Allophylus edulis, presente no compartimento inferior, foram as espécies mais importantes da comunidade florestal da Floresta Ombrófila Mista Aluvial existente no Bosque de Portugal, e semelhante a outras comunidades florestais aluviais da Região 
Metropolitana de Curitiba, conforme resultados apontados nos trabalhos de Carvalho et al. (2009), Curcio et al. (2007), Barddal et al. (2004a e 2004b). Contudo, essas espécies fora da região citada podem ser encontradas em ambientes aluviais de maneira menos expressiva, como é o caso em Campinas, São Paulo (TONIATO et al., 1998), em florestas ribeirinhas no Arroio Passo das Tropas em Santa Maria, Rio Grande do Sul (BUDKE et al., 2004), na bacia do Rio Tibagi, Paraná (DIAS et al., 1998), Parque Estadual Mata dos Godoy em Londrina, Paraná (BIANCHINI et al., 2003).

Ressalta-se que a dominância de uma espécie é consequência do ambiente aluvial sujeito a inundações periódicas, promovendo um contexto homogêneo de menor diversidade do que aquele de florestas situadas em áreas de drenagem livre, como ambiente montanos da mesma tipologia. Logo, as espécies que se apresentam como sendo as mais comuns em qualquer floresta tropical devem ser as mais adaptadas ao regime de perturbação que prevalece no ambiente onde ocorrem (DENSLOW, 1980; HARTSHORN, 1980; RICHARDS, 1979).

\section{CONCLUSÃO}

O remanescente florestal urbano presente no Parque Municipal Bosque de Portugal caracteriza-se como uma Floresta Ombrófila Mista Aluvial com composição florística e estrutura típicas dessa fitologia nos compartimentos superior e intermediário. Assemelha-se a outras florestas da mesma tipologia situadas em outros locais da Região Metropolitana de Curitiba, o que a torna relevante em relação a sua importância ecológica no contexto urbano.

Observa-se a presença de espécies exóticas invasoras utilizadas na arborização e paisagismo urbanos. Porém, devido à baixa representação destas espécies no levantamento fitossociológico realizado, as mesmas não comprometeram a composição florística e a estrutura deste remanescente até o momento.

Aponta-se a necessidade de manejo das espécies exóticas invasoras presentes no local, sendo que a prática mais adequada é a sua retirada da área do Bosque, a fim de garantir a manutenção da estrutura, da composição florística e da dinâmica natural daquela floresta; caso contrário, o processo de sucessão natural 
dessa floresta poderá ser inviabilizado e esse importante remanescente da Floresta Ombrófila Mista Aluvial perderá a sua identidade ecológica.

\section{AGRADECIMENTOS}

Marília Borgo, Daniel Dupré, André Luís Pasdiora e Maciel Batista Paulino.

\section{REFERÊNCIAS}

AB'SABER, A. N. O suporte geológico das florestas beiradeiras (ciliares). In: RODRIGUES, R. R. E LEITÃO-FILHO, H. F (Ed.). Matas ciliares: conservação e recuperação. 2. Ed. São Paulo: Edusp e Fapesp, 2001. Cap. 1.

Angiosperm Phylogeny Group - APG III. An update of the Angiosperm Phylogeny Group classification for the orders and families of flowering plants. Botanical Journal of the Linnean Society, v.161, p. 105-121, 2009.

BARDDAL, M. L.; RODERJAN, C. V.; GALVÃO, F.; CURCIO, G. R. Fitossociologia do sub-bosque de uma Floresta Ombrófila Mista Aluvial, no município de Araucária, PR. Ciência Florestal, v. 14, n. 1, p.35-45, 2004a.

BARDDAL, M. L.; RODERJAN, C. V.; GALVÃO, F.; CURCIO, G. R. Caracterização florística e fitossociológica de um trecho sazonalmente inundável de floresta aluvial, em Araucária, PR. Ciência Florestal, v. 14, n. 2, p. 37-50, 2004b.

BARDDAL, M. L. A influência da saturação hídrica na distribuição de oito espécies arbóreas da Floresta Ombrófila Mista Aluvial do Rio Iguaçu, Paraná, Brasil. 114f. Tese (Doutorado em Ciências Florestais). Universidade Federal do Paraná, Curitiba, Paraná. 2006.

BIANCHINI, E.; POPOLO, R. S.; DIAS, M. C. E PIMENTA, J. A. Diversidade e estrutura de espécies arbóreas em área alagável do município de Londrina, Sul do Brasil. Acta BotanicaBrasilica, v. 17, n. 3, p. 405-419, 2003.

BUDKE, J. C.; GIEHL, E. L. H.; ATHAYDE, E. A.; EISINGER, S. M. E RENATO AQUINO ZÁCHIA, R. A. Florística e fitossociologia do componente arbóreo de uma floresta ribeirinha, arroio Passo das Tropas, Santa Maria, RS, Brasil. Acta Botanica Brasilica, v. 18, n. 3, p. 581-589, 2004.

BUFREN, A. M. Caracterização fitossociológica de um remanescente da floresta ripária do rio Pequeno, São José dos Pinhais - PR. 87f. Dissertação (Mestrado em Ciências Florestais). Universidade Federal do Paraná, Curitiba, Paraná. 1997. 
CARVALHO, J; MARQUES, M. C. M.; RODERJAN, C. V., SOUSA, S. G. A; BARDDAL, M. Relações florísticas e estruturais entre os estratos de uma Floresta Ombrófila Mista Aluvial no Paraná. Acta Botanica Brasilica, v. 23, n. 1, p. 1-9, 2009.

CORDEIRO, J. E RODRIGUES, W. A. Caracterização Fitossociológica de um remanescente de Floresta Ombrófila Mista em Guarapuava, PR. Revista Árvore, v. 31, n. 3, p. 545-554, 2007.

CURCIO, G.R., GALVÃO, F; BONNET, A., BARDDAL, M. L., DEDECEK, R. A. A. Floresta fluvial em dois compartimentos no rio Iguaçu, Paraná, Brasil. Floresta, v. 37, n., p. 125-147, 2007.

CURCIO, G. R.; BONNET, A.; PESTANA, D.; SOUZA, L.; SOCHER, L. G., GALVÃO, F.; RODERJAN, C. V. Compartimentação topossequencial e caracterização fitossociológica de um capão de Floresta Ombrófila Mista. Floresta, v. 36, n. 3, p. 361-369, 2006.

DACANAL, C; LABAKI, L. C.; SILVA, T. M. L. Vamos passear na floresta! O conforto térmico em fragmentos florestais urbanos. Ambiente Construído, v. 10, n. 2, p.115132, 2010.

DAMASCENO JUNIOR, G. A.; SEMIR, J.; SANTOS, F. A. M.; LEITÃO-FILHO, H. F. Tree mortality in a riparian forest at Rio Paraguai, Pantanal, Brazil, after an extreme flooding. Acta Botanica Brasílica, v.18, p.839-846, 2004.

DANTAS, I. C.; SOUZA, C. M. C. Arborização urbana na cidade de Campina Grande - PB: inventário e suas espécies. Revista de Biologia e Ciência da Terra, v. 4, n. 2, 2004.

DENSLOW, J. S. Patterns of plant species diversity during sucession under different disturbance regimes. Oecologia, v. 46, p. 18-21, 1980.

DIAS, M. C., VIEIRA ${ }_{2}$ A. O. S, NAKAJIMA, J. N., PIMENTA J. A E LOBO ${ }_{2}$ P. C. Composição florística e fitossociologia do componente arbóreo das florestas ciliares do rio lapó, na bacia do rio Tibagi, Tibagi, PR. Revista Brasileira de Botânica, v. 21, n. 2, 1998.

FANINI, N. M. (org.). Atlas geográfico do município de Curitiba. SUPERINTENDÊNCIA DA EDUCAÇÃO - SEED; PROGRAMAÇÃO DE DESENVOLVIMETO EDUCACIONAL - PDE. 2008. 47p.

GUIMARÃES, J. C. C., VAN DEN BERG, E., CASTRO, G. C., MACHADO, E. L. M. \& OLIVEIRA-FILHO, A.T. Dinâmica do componente arbustivo-arbóreo de uma floresta de galeria aluvial no planalto de Poços de Caldas, MG, Brasil. Revista Brasileira de Botânica, v.31, n.4, p. 621-632, 2008.

HARTSHORN. G. S. Neotropical Forest dynamics. Biotropica, 12, pg.23-30, 1980. 
INSTITUTO AMBIENTAL DO PARANÁ - IAP. Unidades de Conservação: Ações para a Valorização da Biodiversidade. Curitiba. IAP. 2006. 344 p.

INSTITUTO BRASILEIRO DE GEOGRAFIA E ESTATÍSTICA - IBGE. Manual Técnico da Vegetação Brasileira. Série Manuais Técnicos em Geociências. Rio de Janeiro. 2012.

INSTITUTO DE RECURSOS MUNDIAIS; UNIÃO MUNDIAL PARA A NATUREZA; PROGRAMA DAS NAÇÕES UNIDAS PARA O MEIO AMBIENTE (1992). A estratégia global para a biodiversidade - diretrizes de ação para estudar, salvar e usar de maneira sustentável e justa a riqueza biota da Terra. Curitiba: World resources Institute/ Fundação O Boticário de Proteção a Natureza. 1992. 232 p.

KLAUBERG, C.; PALUDO, G. F.; BORTOLUZZI, R. L. C; MANTOVANI, A. (2010). Florística e estrutura de um fragmento de Floresta Ombrófila Mista no Planalto Catarinense. Biotemas, v. 23, n. 1, p. 35-47, 2010.

KLEIN, R. M.; HATSCHBACH, G. Fitofisionomia e notas sobre a vegetação para acompanhar a planta fitogeográfica do município de Curitiba e arredores. Boletim da Universidade Federal do Paraná. Geografia Física, v. 4, n. 30, 1962.

KOSERA, C.; DITTRICH, V. A. O.; SILVA, S. M. Composição florística da Floresta Ombrófila Mista Montana do Parque Municipal do Barigui, Curitiba, PR. Floresta, v. 36 , n. 1, p. 45-58, 2006 a.

KOSERA, C.; DITTRICH, V. A. O.; SILVA, S. M. Fitossociologia do componente arbóreo de um fragmento de Floresta Ombrófila Mista Montana, Curitiba, PR, BR. Floresta, v. 36, n. 2, p. 226-237, 2006b.

LEITE, P. F. As diferentes unidades fitoecológicas da região sul do Brasil proposta de classificação. 160f. Dissertação (Mestrado em Ciências Florestais) Setor de Ciências Agrárias. Universidade Federal do Paraná, Curitiba. 1994.

LIRA-FILHO, J. A., MEDEIROS, M. A. S. Impactos adversos na avifaunapelas atividades de arborização urbana. Revista de Biologia e Ciência da Terra, v. 6, n. 2, p. $375-390,2006$.

MARGURRAN, A. E. Diversidade ecológica y su medición. Barcelona: Ediciones Vedrá, 1989.

MISSOURI BOTANICAL GARDEN. Vascular Trópicos (VAST) nomenclatural database and associated authority files, 1968 Disponível em: http://www.mobot.org/w3t/search/vast.html. Acesso: 28/01/2014.

MUELLER-DOMBOIS, D.; ELLENBERG. Aims and Methods of Vegetation Ecology. New York: J, Wiley e Sons. 1974. 525 p.

NASCIMENTO, A. R. T.; LONGHI, S. J. E BRENA, D. Estrutura e padrões de 
distribuição espacial de espécies arbóreas em uma amostra de Floresta Ombrófila Mista em Nova Prata, RS. Ciência Florestal, v.11, n. 1, p.105-119, 2001.

OLIVEIRA, M. Perfil ambiental de uma metrópole brasileira: Curitiba, seus parques e bosques. Revista Paraná Desenvolvimento, v. 88, p. 37-54, 1996.

PAULA, P. F. E FERREIRA, M. E. M. C. 2005. Levantamento fitogeográfico preliminar no Parque do Cinquentenário em Maringá-PR. Revista Geografia, v. 14, n. 1, p. 73-86, 2005.

PROGRAMA GLOBAL DE ESPÉCIES INVASORAS. América do Sul Invadida: A crescente ameaça das espécies exóticas invasoras. 2005. 80p. Disponível em: http://www.curitiba.pr.gov.br/Servicos/MeioAmbiente/areas_verdes/parques_bosques /bosque_portugal. Acesso: 23/08/2012.

RICHARDS, M. A. The Tropical Rain Forest: an ecological study. London: Cambridge University Press. 1979. 450p.

RODERJAN, C. V.; GALVÃO, F.; KUNIYOSHI, Y. S.; HATSCHBACH, G. G. As Unidades Fitogeográficas do Estado do Paraná. Ciência \& Ambiente. Fitogeografia do Sul da América, v. 24, p. 75 - 92, 2002.

ROSEIRA, D. S. (1990). Composição Florística e Estrutura Fitossociológica do Bosque com Araucária angustifólia (Bert.) O.Ktze no Parque Estadual João Paulo II, Curitiba - PR. 11f. Dissertação (Mestrado em Ciências Biológicas). Universidade Federal do Paraná, Curitiba, Paraná. 1990.

SALAMENE, S.; FRANCELINO, M. R.; VALCARCEL, R.; LANI, J. L.; MÉDICE, M. SÁ, F. Estratificação e caracterização ambiental da área de Preservação Permanente do rio Guandu/RJ. Revista Árvore, v. 35, n. 2, p. 221-231, 2011.

SANTANA, O. A. E ENCINAS, J.I. Levantamento das espécies exóticas arbóreas e seu impacto nas espécies nativas em áreas adjacentes a depósitos de resíduos domiciliares. Biotemas, v. 21, n. 4, p. 29-38, 2008.

SECRETARIA MUNICIPAL DO MEIO AMBIENTE - SMMA. Decreto 9.804. 2000

SECRETARIA MUNICIPAL DO MEIO AMBIENTE - SMMA. Decreto 848. 1995.

SECRETARIA MUNICIPAL DO MEIO AMBIENTE - SMMA. Parques e praças de Curitiba. Disponível em http://www.parquesepracasdecuritiba.com.br/parques/bosque-de-portugal.html. Acesso em 20/11/2013.

SELUSNIAKI, M.; ACRA, L. A. O componente arbóreo-arbustivo de um remanescente de Floresta com Araucária no município de Curitiba, Paraná. Floresta, Curitiba, v. 40, n. 3, p. 593-602, 2010. 
SILVA, A. C.; VAN DEN BERG, E; HIGUCHI, P.; NUNES, M. H. Dinâmica de uma comunidade arbórea após enchente em fragmentos florestais no sul de Minas Gerais. Revista Árvore, v. 35, n.4, p. 883-893, 2011.

TONIATO, M. T. Z., LEITÃO-FILHO, H. F., RODRIGUES, R.R. Fitossociolgoia de um remanescente de floresta higrófila (mata de brejo), em Campinas, SP. Revista Brasileira de Botânica, v. 21, n. 2, p. 45- 58, 1998.

VIGILIATO, G. R.; ZAMPAR, R. Susceptibilidade das zonas de recuperação de uma unidade de conservação à invasão biológica por espécies arbóreas exóticas. Revista de Saúde e Biologia, v.6, n. 3, p. 25-37, 2011.

ZILLER, S. R.; HATSCHBACH, G. As Formações Vegetais da Área de Influência do Futuro Reservatório do Rio Iraí Piraquara / Quatro Barras - PR. Curitiba, Relatório Técnico. 1993. 93p.

(Recebido em 29.01.2014; Aceito em: 26.06.2014) 